Scandium Molybdate Nanofibers with Negative Thermal Expansion for Fabricating Composites with Controllable

\title{
Coefficient of Thermal Expansion
}

Hongfei Liu,,${ }^{\dagger}$ Chenjun Zhang, ${ }^{\dagger}$ Weikang Sun, ${ }^{\dagger}$ Zhiping Zhang, ${ }^{*}, \dagger$ Min $Z$ Zhou, ${ }^{\dagger}$ Wei

Wang, ${ }^{\dagger}$ Xiaobing Chen,$\dagger$, Xianghua Zeng, ${ }^{\dagger}$

†School of Physical Science and Technology, Yangzhou University, Yang zhou, 225002, PR China

tDepartment of Mechanical and Electrical Engineering, Guangling College, Yang zhou University, Yang zhou, 225000, PR China

\section{Corresponding Authors}

*E-mail: liuhf@yzu.edu.cn (Hongfei Liu)

*E-mail: zhiping@yzu.edu.cn (Zhiping Zhang)

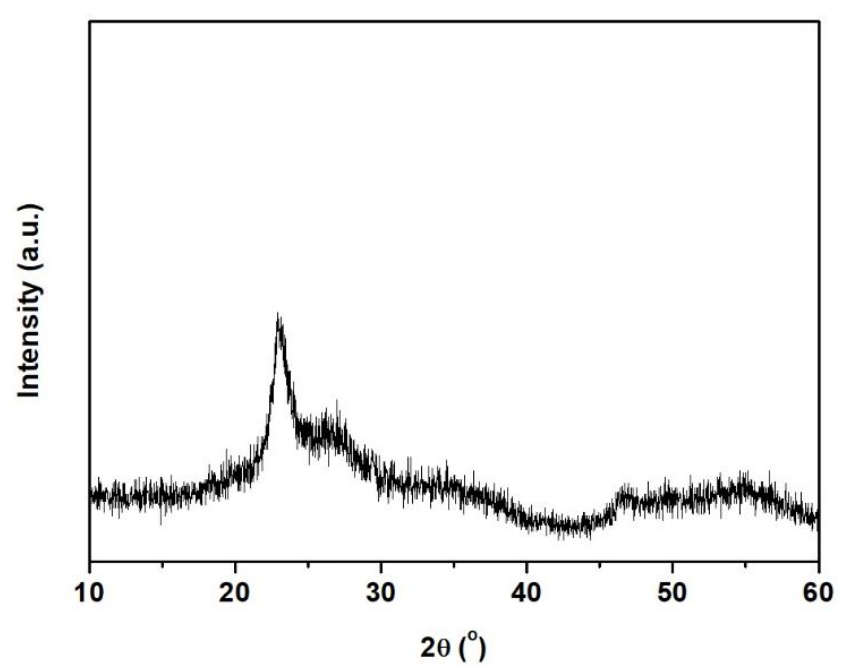

Figure S1. Typical XRD pattern of the as-prepared $\mathrm{Sc}_{2} \mathrm{Mo}_{3} \mathrm{O}_{12}$ nanofibers dried at $85^{\circ} \mathrm{C}$. 